
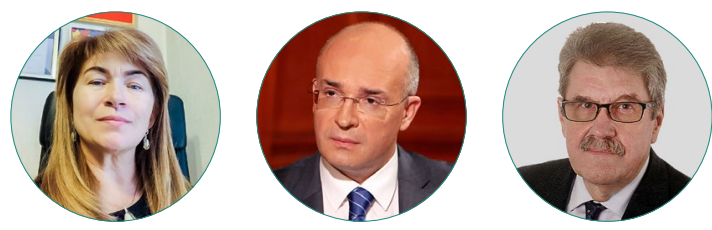

Л. Е. Ильичева, А. О. Кондрашов, А. В. Лапин

\title{
ДОВЕРИЕ КАК МОСТ НАД ПРОПАСТЬЮ НЕУВЕРЕННОСТИ МЕЖДУ ВЛАСТЬЮ И ОБЩЕСТВОМ
}

\section{Правильная ссылка на статью:}

Ильичева Л.Е., Кондрашов А. О., Лапин А.В. Доверие как мост над пропастью неуверенности между властью и обществом // Мониторинг общественного мнения: экономические и социальные перемены. 2021. № 2. С. 162-185. https://doi.org/10.14515/monitoring. 2021.2.1917.

\section{For citation:}

Iliycheva L. E., Kondrashov A. O., Lapin A. V. (2021) Trust as a Bridge Over the Uncertainty Gap Between the Government and Society. Monitoring of Public Opinion: Economic and Social Changes. No. 2. P. 162-185. https://doi.org/10.14515/monitoring.2021.2.1917. (In Russ.) 
ДОВЕРИЕ КАК МОСТ НАД ПРОПАСТЬЮ НЕУВЕРЕННОСТИ МЕЖДУ ВЛАСТЬЮ И ОБЩЕСТВОМ

ИЛЬИЧЕВА Людмила Ефимовна - доктор политических наук, профессор, Российская академия народного хозяйства и государственной службы при Президенте РФ, Москва, Россия; главный научный сотрудник, Институт социально-политических исследований Федерального научно-исследовательского социологического центра Российской академии наук, Москва, Россия

E-MAIL: lilitcheva@mail.ru https://orcid.org/0000-0002-0223-6418

КОНДРАШОВ Андрей Олегович - магистр политологии, соискатель, Институт социально-политических исследований Федерального научно-исследовательского социологического центра Российской академии наук, Москва, Россия E-MAIL: akondrashov@vgtrk.ru https://orcid.org/0000-0001-9846-2489

ЛАПИН Андрей Викторович - кандидат политических наук, доцент, Центр государственно-частного партнерства Института государственной службы и управления Российской академии народного хозяйства и государственной службы при Президенте Российской Федерации, Москва, Россия

E-MAIL:av.lapin@igsu.ru https://orcid.org/0000-0002-9663-3763

Аннотация. В сложившихся условиях повышенных социальных рисков, связанных с негативными правовыми, духовными и морально-этическими последствиями перехода в новый цифровой технологический уклад, актуализация проблемы доверия населения
TRUST AS A BRIDGE OVER THE UNCERTAINTY GAP BETWEEN THE GOVERNMENT AND SOCIETY

Ludmila E. ILIYCHEVA ${ }^{1,2}$-Dr. Sci. (Polit.), Professor; Principal Researcher

E-MAIL: lilitcheva@mail.ru

https://orcid.org/0000-0002-0223-6418

Andrey O. KONDRASHOV 2 - Master of Political Science

E-MAIL: akondrashov@vgtrk.ru

https://orcid.org/0000-0001-9846-2489

Andrey V. LAPIN ${ }^{3}$ - Cand. Sci. (Polit.), Associate Professor

E-MAIL:av.lapin@igsu.ru https://orcid.org/0000-0002-9663-3763

\footnotetext{
${ }^{1}$ Russian Presidential Academy of National Economy and Public Administration, Moscow, Russia

2 Institute for Socio-Political Research of the Federal Center of Theretical and Applied Sociology of the Russian Academy of Sciences, Moscow, Russia

${ }^{3}$ Center for Public-Private Partnership of the Institute of Public Administration and Management of the Russian Presidential Academy of National Economy and Public Administration, Moscow, Russia
}

Abstract. The present time is characterized by an increase in social risks, which are associated with negative legal, spiritual, moral and ethical consequences of the transition to a new digital technological structure. This leads to an increase in the gap between the 
к власти вызвана растущим разрывом между социально-экономическими и политическими ожиданиями людей и выполнением властью своих обещаний. В этих обстоятельствах доверие к проводимой государством политике становится ключевым фактором, способным придать гражданам уверенность в будущем, повысить их личную ответственность и эффективность их деятельности. Доверие детерминировано общей мировоззренческой позицией власти, бизнеса и гражданского общества по основным приоритетам и важнейшим направлениям развития, закрепляемым в соответствующем общественном договоре. В таком обществе участники могут ассоциировать себя с конструктом "мы-группа", означающим взаимное доверие и учет интересов других в соответствии с духом солидарности. Анализ предпосылок и вероятных путей достижения состояния "мы-группа", предпринятый в статье, показывает принципиальную возможность управления доверием населения к власти путем согласования интересов основных акторов.

Ключевые слова: политическое доверие, общественный договор, государство как платформа, социальная норма, политические сети, баланс интересов и морали

Благодарность. Благодарность. Статья написана при финансовой поддержке РФФИ, грант № 20-011-31357 «Технологии управления доверием к власти, упреждения угроз и вызовов региональной социально-политической стабильности". socio-economic and political expectations of people, on the one hand, and the fulfillment of their promises by the authorities, on the other. For this reason, the problem of public trust in the authorities is of great importance. In these circumstances, trust in the state policy becomes a key factor that gives citizens confidence in the future, increases their personal responsibility and the effectiveness of their activities. Trust is based on the common ideological position of the authorities, business and civil society on the main priorities and the most important areas of development, enshrined in the corresponding social contract. In such a society, participants may associate themselves with the "we-group" that means mutual trust and solidarity. The article analyzes the prerequisites and ways to achieve the state of "we are a group" and shows the fundamental possibility of managing public trust in the government by harmonizing the interests of the main actors.

Keywords: political trust, social contract, state as a platform, social norm, political networks, interests-morality balance

Acknowledgments. The article was written with the financial support of the Russian Foundation for Basic Research, Grant No. 20-011-31357 "Ways to manage trust in the authorities, forestall threats and challenges to regional socio-political stability". 
Продолжающаяся пандемия COVID-19 подтвердила вывод о ведущей роли национального государства как главного элемента современной системы глобального управления, обеспечивающего производство всеобщих благ даже в ситуации, близкой к "идеальному шторму", бушующему в мире [Громыко, 2020]. Накопленные возможности России в области здравоохранения, а также умение власти принудить граждан к ограничению их свобод во имя препятствования распространению коронавируса могут вполне успешно противостоять вызовам непрекращающейся пандемии. Готовность граждан страны соблюдать вводимые государством ограничения выступает признаком стабильного уровня доверия общества к федеральной власти, продемонстрировавшей решительность и надежность в условиях крайней неопределенности, связанной с недостатком информации об особенностях вируса. В этой связи интересны результаты опроса ВЦИОМ, проведенного в декабре 2020 г.: $56 \%$ россиян считают, что вследствие пандемии коронавируса усилилось единство между людьми, $11 \%$ - что сложные ситуации объединяют, $6 \%$ - что нужно полагаться друг на друга ${ }^{1}$. Кроме того, возросла гражданская активность россиян: например, 71\% опрошенных заявили, что совершали какое-либо общественно полезное дело, помогали другим, 59 \% респондентов отметили, что люди стали чаще заниматься волонтерской или добровольческой деятельностью ${ }^{2}$.

Тенденция сохранения доминанты общественных интересов над личными подтверждается результатами исследования, проведённого Институтом общественного мнения "Квалитас" совместно с ИСПИ ФНИСЦ РАН в 2011-2014 гг., согласно которым заметно снизилась доля респондентов, считающих, что интересы отдельного человека выше, чем интересы общества (см. табл. 1).

Таблица 1. Изменение соотношения общественных и личных интересов в разных возрастных группах (\% от числа опрошенных)*

\begin{tabular}{|c|c|c|c|c|c|c|c|c|c|c|c|c|}
\hline \multirow{3}{*}{ Возраст } & \multicolumn{6}{|c|}{$\begin{array}{c}\text { Приоритет общественных } \\
\text { или личных интересов }\end{array}$} & \multicolumn{6}{|c|}{$\begin{array}{c}\text { Готовность (неготовность) } \\
\text { жертвовать личными интересами }\end{array}$} \\
\hline & \multicolumn{2}{|c|}{$\begin{array}{l}\text { Интересы об- } \\
\text { щества в це- } \\
\text { лом выше, } \\
\text { чем интересы } \\
\text { отдельного } \\
\text { человека }\end{array}$} & \multicolumn{2}{|c|}{$\begin{array}{c}\text { Интересы от- } \\
\text { дельного че- } \\
\text { ловека выше, } \\
\text { чем интересы } \\
\text { общества }\end{array}$} & \multicolumn{2}{|c|}{$\begin{array}{l}\text { Затруднились } \\
\text { с ответом }\end{array}$} & \multicolumn{2}{|c|}{$\begin{array}{c}\text { Человек дол- } \\
\text { жен жертво- } \\
\text { вать своими } \\
\text { интересами } \\
\text { ради интере- } \\
\text { сов других } \\
\text { людей }\end{array}$} & \multicolumn{2}{|c|}{$\begin{array}{c}\text { Человек дол- } \\
\text { жен бороться } \\
\text { за свои инте- } \\
\text { ресы, даже } \\
\text { если они } \\
\text { противоречат } \\
\text { интересам } \\
\text { других людей }\end{array}$} & \multicolumn{2}{|c|}{$\begin{array}{l}\text { Затруднились } \\
\text { с ответом }\end{array}$} \\
\hline & 2011 & 2014 & 2011 & 2014 & 2011 & 2014 & 2011 & 2014 & 2011 & 2014 & 2011 & 2014 \\
\hline $18-24$ & 60,7 & 63,2 & 33,3 & 26,8 & 6,0 & 10,0 & 32,2 & 32,6 & 56,8 & 52,6 & 10,9 & 14,7 \\
\hline $25-29$ & 59,3 & 64,9 & 35,0 & 27,7 & 5,7 & 7,4 & 35,0 & 35,1 & 47,9 & 49,3 & 17,1 & 15,5 \\
\hline $30-39$ & 56,8 & 59,5 & 33,9 & 33,2 & 9,3 & 7,3 & 36,0 & 29,3 & 49,2 & 52,9 & 14,8 & 17,8 \\
\hline $40-49$ & 58,1 & 63,4 & 34,7 & 26,4 & 7,2 & 10,2 & 33,1 & 34,0 & 49,2 & 46,4 & 17,8 & 19,6 \\
\hline $50-59$ & 64,8 & 66,9 & 27,5 & 26,5 & 7,7 & 6,5 & 45,5 & 32,3 & 42,1 & 53,8 & 12,4 & 13,8 \\
\hline $\begin{array}{c}60 \text { лет } \\
\text { и старше }\end{array}$ & 60,4 & 63,5 & 29,7 & 28,3 & 9,9 & 8,2 & 46,5 & 42,1 & 35,5 & 43,8 & 17,9 & 14,1 \\
\hline
\end{tabular}

* Источник: [Чупров, Зубок, Романович, 2019: 120].

\footnotetext{
1 Солидарность на фоне пандемии (Аналитический обзор)// ВЦиОМ. 2020. 29 декабря. URL: https://wciom.ru/ analytical-reviews/analiticheskii-obzor/solidarnost-na-fone-pandemii (дата обращения: 25.04.2021).

2 Там же.
} 
Эти факты свидетельствует о зримо возросшей социальной ответственности наших граждан за свои поступки, о нарастании их социальной активности, однако осознанное повышение требовательности к себе вызывает усиление критического, взыскательного отношения россиян и к власти как к стороне, отвечающей за состояние гражданского общества и социального государства. Претензии людей к власти формируют соответствующий перечень социальных проблем, список которых по результатам опроса ИСПИ ФНИСЦ РАН в августе-сентябре 2020 г. представлен в таблице 2.

Таблица 2. Проблемы, беспокоящие респондентов (\% от числа опрошенных)*

\begin{tabular}{|l|c|c|c|}
\hline \multicolumn{1}{|c|}{ Наименование проблемы } & $\begin{array}{c}\text { Декабрь } \\
\mathbf{2 0 1 0}\end{array}$ & $\begin{array}{c}\text { Декабрь } \\
\mathbf{2 0 1 5}\end{array}$ & $\begin{array}{c}\text { Сентябрь } \\
\mathbf{2 0 2 0}\end{array}$ \\
\hline Дороговизна жизни & 53 & 58 & 61 \\
\hline Экологическая обстановка & 33 & 22 & 39 \\
\hline Безработица & 29 & 28 & 34 \\
\hline Повышение цен на продукты питания & 39 & 34 & 32 \\
\hline Повышение тарифов на услуги ЖКХ & 43 & 31 & 31 \\
\hline Разделение общества на богатых и бедных & 18 & 24 & 29 \\
\hline Произвол чиновников & 35 & 33 & 28 \\
\hline Безопасность Ваша и Ваших близких & 27 & 26 & 25 \\
\hline Страх перед будущим & - & 19 & 19 \\
\hline Преступность & 30 & 19 & 17 \\
\hline Ухудшение положения пенсионеров в обществе & - & 13 & 16 \\
\hline
\end{tabular}

* Источник: [Российское общество..., 2020: 13].

\section{Доверие в неопределенном мире}

Последние социологические исследования показывают, что ожидания россиян начинают смещаться в негативную сторону. Так, рассчитываемый Вциом индекс социального оптимизма осенью 2020 г. показал достаточно низкий уровень - минус 61 п. (в июне 2020 г. этот индекс составлял минус 42 п.), при этом $60 \%$ наших соотечественников считают, что экономический кризис еще впереди ${ }^{3}$. Эти данные подтверждаются опросами "Левада-центра", который зафиксировал в августе 2020 г. снижение сводного индекса общественных настроений на $7 \%$ по сравнению с февралем ${ }^{4}$, а Росстат, в свою очередь, определил индекс потребительской уверенности в III квартале 2020 г. на уровне минус 22 п., что гораздо ниже показателя I квартала того же года (минус 11 п.) $)^{5}$.

Ухудшение настроений, связанных с надеждами на лучшее, пока еще не рассматривается как четко выраженный тренд - скорее, можно говорить, что общество находится на некотором переломном этапе между состоянием готовности к трудно-

\footnotetext{
${ }^{3}$ Социальное самочувствие россиян: мониторинг (Аналитический обзор) // ВЦиОМ. 2020. 19 октября. URL: https:// wciom.ru/analytical-reviews/analiticheskii-obzor/soczialnoe-samochuvstvie-rossiyan-monitoring (дата обращения: 25.04.2021).

4 Общественные настроения в августе 2020 г. (пресс-выпуск) //URL: https://www.levada.ru/2020/09/14/ obshhestvennye-nastroeniya-v-avguste-2020-g/ (дата обращения: 25.04.2021).

5 Уровень жизни. Потребительские ожидания населения. Индекс потребительской уверенности (официальная статистика)// Росстат. 2020. Октябрь. URL: https://rosstat.gov.ru/folder/13397 (дата обращения: 25.04.2021).
} 
стям и накопленной усталостью от постоянного ожидания ясности своего будущего положения. В этом непрозрачном, пропитанном неясностью и неуверенностью контексте, как писал П. Штомпка, "для того, чтобы жить и функционировать в обществе, мы должны постоянно предпринимать „прыжки в неуверенность“, тестируя окружающий мир в поисках тех лиц, устройств, продуктов, организаций, идей, которые будут нам нужны, выгодны, полезны, необходимы" [Штомпка, 2012: 31].

Несмотря на некоторое повышение гражданской активности, россияне в условиях изменяющейся социальной реальности все еще предпочитают тестировать окружающий мир не в одиночку, а полагаясь на содействие политической власти, от которой ожидают проявления традиционного государственного патернализма. Этот тезис подтверждается результатами ранее указанного опроса Института общественного мнения "Квалитас" . проведенного совместно с ИСПИ ФНИСЦ РАН в 2011-2014 гг., который четко зафиксировал доминирование ролей традиционной модели власти, где установки на ее персонификацию и централизацию преобладают над деперсонификацией, характерной для современной западной политической культуры (см. табл. 3).

Таблица З. Изменение отношения к традиционной и современной моделям власти (\% от числа ответивших)*

\begin{tabular}{|c|c|c|c|c|c|c|c|}
\hline \multicolumn{3}{|c|}{ Традиционная модель } & \multicolumn{3}{|c|}{ Современная модель } & \multicolumn{2}{|c|}{$\begin{array}{c}\text { Затруднились } \\
\text { ответить }\end{array}$} \\
\hline & 2011 & 2014 & & 2011 & 2014 & 2011 & 2014 \\
\hline $\begin{array}{l}\text { Сильный лидер, умею- } \\
\text { щий сосредоточить } \\
\text { в своих руках всю полно- } \\
\text { ту власти }\end{array}$ & 72,6 & 71,8 & $\begin{array}{l}\text { Сильные политические } \\
\text { партии }\end{array}$ & 17,5 & 20,5 & 9,8 & 7,7 \\
\hline $\begin{array}{l}\text { Монолитное государство } \\
\text { с управлением из одного } \\
\text { центра }\end{array}$ & 52,4 & 53,5 & $\begin{array}{l}\text { Самостоятельность } \\
\text { регионов }\end{array}$ & 38,5 & 37,4 & 9,1 & 9,5 \\
\hline $\begin{array}{l}\text { Умный, мудрый и чест- } \\
\text { ный руководитель }\end{array}$ & 70,8 & 73,1 & $\begin{array}{l}\text { Не важно, кто управля- } \\
\text { ет страной, важно, что- } \\
\text { бы он соблюдал закон } \\
\end{array}$ & 24,4 & 22,5 & 4,8 & 4,3 \\
\hline $\begin{array}{l}\text { В стране должен быть } \\
\text { хозяин - нашему народу } \\
\text { нужна сильная рука }\end{array}$ & 65,5 & 61,8 & $\begin{array}{l}\text { Нельзя допускать, } \\
\text { чтобы власть в России } \\
\text { была отдана в руки } \\
\text { одного человека }\end{array}$ & 24,7 & 28,2 & 9,8 & 9,9 \\
\hline $\begin{array}{l}\text { Парламент должен быть } \\
\text { ответственен перед } \\
\text { президентом РФ }\end{array}$ & 49,3 & 49,4 & $\begin{array}{l}\text { Парламент должен быть } \\
\text { независим } \\
\text { от президента РФ }\end{array}$ & 34,8 & 37,4 & 15,8 & 13,2 \\
\hline $\begin{array}{l}\text { Суд должен быть ответ- } \\
\text { ственен перед } \\
\text { президентом РФ }\end{array}$ & 34,5 & 34,7 & $\begin{array}{l}\text { Суд должен } \\
\text { быть независим } \\
\text { от президента РФ }\end{array}$ & 52,9 & 55,4 & 12,6 & 9,8 \\
\hline $\begin{array}{l}\text { Губернатор должен отве- } \\
\text { чать перед } \\
\text { президентом РФ }\end{array}$ & 46,3 & 51,7 & $\begin{array}{l}\text { Губернатор должен } \\
\text { отвечать только перед } \\
\text { народом, избравшим } \\
\text { его }\end{array}$ & 40,7 & 37,6 & 13,0 & 10,8 \\
\hline $\begin{array}{l}\text { Мэр должен отвечать } \\
\text { перед губернатором }\end{array}$ & 38,5 & 51,7 & $\begin{array}{l}\text { Мэр должен отвечать } \\
\text { только перед народом, } \\
\text { избравшим его }\end{array}$ & 47,3 & 37,6 & 14,1 & 10,8 \\
\hline
\end{tabular}




\begin{tabular}{|l|c|c|l|c|c|c|c|}
\hline \multicolumn{3}{|c|}{ традиционная модель } & \multicolumn{3}{c|}{ Современная модель } & \multicolumn{3}{c|}{$\begin{array}{l}\text { Затруднились } \\
\text { ответить }\end{array}$} \\
\hline & $\mathbf{2 0 1 1}$ & $\mathbf{2 0 1 4}$ & & $\mathbf{2 0 1 1}$ & $\mathbf{2 0 1 4}$ & $\mathbf{2 0 1 1}$ & $\mathbf{2 0 1 4}$ \\
\hline $\begin{array}{l}\text { Областная дума долж- } \\
\text { на отвечать перед } \\
\text { губернатором }\end{array}$ & 42,8 & - & $\begin{array}{l}\text { Областная дума долж- } \\
\text { на быть независима } \\
\text { от губернатора }\end{array}$ & 37,8 & - & 19,5 & - \\
\hline $\begin{array}{l}\text { Городская дума должна } \\
\text { отвечать перед мэром }\end{array}$ & 42,7 & - & $\begin{array}{l}\text { Городская дума долж- } \\
\text { на быть независима } \\
\text { от мэра }\end{array}$ & 37,7 & - & 19,6 & - \\
\hline
\end{tabular}

* Источник: [Чупров, Зубок, Романович, 2019: 103].

Сведения, представленные в таблице 3, свидетельствуют о том, что в России продолжает действовать запрос на укрепление властной вертикали, на развитие иерархической соподчиненности между федеральным центром и регионами, а число сторонников разделения властей снижается (кроме вопросов, связанных с независимостью суда, по которому количество поддерживающих независимый суд превышает количество противников такого подхода).

Представленные данные исследований можно интерпретировать как противоречивые: с одной стороны, в обществе формируется большая группа граждан, которые рассчитывают на собственные силы и готовы жертвовать своим личным временем и ресурсами ради удовлетворения общественных интересов; с другой стороны, эта готовность поступиться личным во имя общественного пока еще не переросла в индивидуальную политическую активность и ограничивается в основном использованием права избрания своих представителей во власть для того, чтобы потом потребовать от нее в целом (а не от своих представителей, которые были избраны) выполнения актуальных социально-политических и экономических запросов.

Это противоречие может быть объяснено присущей россиянам неуверенностью, заключающейся в том, что их возможные действия, произведенные из самых лучших побуждений, могут квалифицироваться властью как нежелательные, непрофессиональные или просто опасные. Выраженное же властью недовольство такими инициативами может быть воспринято деятельными гражданами как серьезная моральная травма, разочарование в своих способностях генерировать осознанные, взвешенные и конструктивные решения в интересах всего общества. Люди вполне резонно опасаются, что власть может применить к ним незаслуженные, обидные с их точки зрения санкции, знаменующие, по сути, отчуждение у граждан права на ошибку. Это ведет к параличу воли к осуществлению самостоятельных инициатив.

Отсутствие понимания возможных последствий и глубины предполагаемого наказания за отклонение от линии власти с большой долей вероятности будет формировать в людях неуверенность и апатию, что не способствует преодолению кризисных явлений в стране и совершению "решительных прорывов", требующих активных шагов, использования нестандартных подходов и применения творческого начала. В свою очередь, декларируя призыв к гражданам проявлять инициативу, лидерские качества и предпринимательский подход, чиновники в изменяющейся социальной реальности на деле будут всячески избегать входа в зону собственной неуверенности, которая, как правило, находится за рамками устоявшихся шаблонов поведения облеченных властью. 
Выход из этого противоречия, на наш взгляд, лежит на пути признания права как граждан, так и власти совершать естественные ошибки, что подразумевает обязанность совместно принимать на себя возможные риски в процессе государственного и общественного развития в случае какого-либо просчета. Так совершается переход от деятельности в рамках концепции "нулевого" риска к работе по концепции "приемлемого" риска, который можно оценить прогностическими и иными методами еще на стадии принятия социально-политического или экономического решения. Этот подход предполагает необходимость выстраивания системы взаимного общественного и государственного контроля, совершенствования коммуникаций и обратной связи между гражданами и властью с целью своевременного обнаружения и исправления произошедших оплошностей. Другими словами, для обретения уверенности граждан и чиновников в столь неопределенном мире нам нужно доверие в качестве «человеческого моста над пропастью неуверенности" [Штомпка, 2012: 31], разделяющей общество и власть.

Только устойчивое взаимное доверие между властью и обществом позволит даже в случае совершения какого-либо промаха не опустить руки, собраться с силами и выработать оптимальное решение, направленное на преодоление ключевых проблем. Доверие раскрепостит сознание людей, "обнулит" страх ответственности за случайный неверный проступок и тем самым привнесет в совместную деятельность власти и общества элементы энтузиазма и свободы, превращающие рутину повседневной деятельности в творческую гражданскую активность, так необходимую нам для смелого, плодотворного и созидательного сотрудничества в этот кризисный период времени.

Размышляя о причинах противоречивого и неуверенного поведения власти и общества в условиях неопределенности, следует осознать, что государство все же надлежит воспринимать как неотьемлемую часть сообщества, которому присуща не только коалиция интересов, в том числе властных, но и мораль, и если интересы оказываются носителями центробежных признаков, то мораль связывает социум в единый организм, наделенный общим смыслом. Мораль становится средством самореализации, а моральный мотив, сочетающийся с личным интересом, усиливает удовольствие от удовлетворения высших социальных потребностей человека [Разин, 2013]. Моральное сообщество, как заметил Ф. Фукуяма, опирается на этические обычаи и взаимные моральные обязательства между его членами [Фукуяма, 2004].

Принимая эту точку зрения, можно заметить, что моральное пространство нашего общества, несмотря на разность интересов его членов, допускает внутри него образование совокупностей личностей, характер отношений между которыми позволяет их отнести к той или иной группе “мы". Как говорил П. Штомпка, "„мы“ - это те, кого мы наделяем доверием, в отношении которых поступаем лояльно и об интересах которых беспокоимся в соответствии с духом солидарности" [Штомпка, 2012: 44-45].

\section{Конструкт "мы-группа"}

Наделяя доверием "других" внутри круга "мы", возможно также определить и объект, вокруг которого будут конструироваться доверительные отношения. Один из основоположников феноменологической социологии А. Шюц считал, что 
конструкт "Мы" включает в себя не только "тебя" и "меня", но "каждого, кто является одним из нас", подразумевая под "каждым" тех, чья система релевантностей по существу и в достаточной степени совпадает с "твоей" и "моей", и наши точки зрения взаимозаменяемы [Шюц, 1988]. Важным элементом в системе знаний по А. Шюцу выступает объект знания, характеристики которого, познанные “мною" и потенциально познаваемые "тобой", расцениваются как знание "каждого", само собой разумеющееся. В качестве объекта знания, который принят "каждым", кто разделяет соответствующую систему релевантностей, А. Шюц определил образ жизни, рассматриваемый членами "мы-группы" как естественный, нормальный и правильный, являющийся источником привычек, нравов, традиционного поведения, типичных истин, наличествующих в «мы-группе».

Развитие знания об объекте, вокруг которого формируется "мы-группа", а также о жизненном мире "других" членов сообщества позволяет углубить наше понимание субъективных смыслов социальных действий участников и ощутить изменяющуюся социальную реальность в процессе проектирования объекта, на котором фокусируется групповое внимание. Роль "другого" конструируется "Мною" как роль частной личности, исполнителя типичных ролей и функций, во взаимодействии с которым "я" принимаю свою роль не как целостная личность, а фрагментарно, тем самым "я" самотипизирую свое поведение, связанное с "другим". А. Шюц считал, что, познавая окружающую среду, "мы-группы" строят соответствующую анонимную унифицированную точку зрения на типичные конструкты образа жизни, взаимодействия со средой, рекомендации по использованию типичных средств для достижения типичных целей в типичных ситуациях.

Как следствие, разным системам релевантностей и связанным с ними образам жизни будут соответствовать и разные "мы-группы", в каждой из которых "я" "другого" человека конструируется ожиданием его поведения по типичному способу деятельности, типичным мотивам и установкам типа личности. Это означает, что взаимодействие внутри каждой из таких “мы-групп" может быть выстроено на доверительных отношениях только в том случае, когда индивид будет чувствовать себя как бы среди "своих" и его ожидания будут совпадать в той или иной степени со взглядами "других".

Проектируя образ жизни как некую будущую цель, "Мы-группа" представляет в своем воображении завершенное положение дел, к которому приведет будущая деятельность, и затем реконструирует в своем воображении отдельные этапы, ведущие к цели. Вывод А. Шюца заключается в том, что возможность понять "другого" в той мере, которая достаточна для достижения наличной цели, носит вероятностный характер, и чтобы увеличить эту вероятность, нужно выявлять смысл, набор мотивов, управляющих действиями "других". Этот набор будет конструктом типичных ожиданий от поведения "другого", особенно важных при проектировании действий, ориентированных на реакцию не только партнеров, но и простых граждан: “я" ожидаю, что “другой» будет руководствоваться теми же типами мотивов, которыми "я" и многие "другие" руководствовались в прошлом при сходных обстоятельствах.

В рамках модели "мы-группа" большинство личностных и поведенческих типических конструктов институализируется в формате стандартов поведения, 
поддерживаемых обычаями и традициями, а иногда и особыми средствами социального контроля, называемыми законами. Чем более институализирована и стандартизована с помощью законов, правил, норм, обычаев, традиций и т. п. модель взаимосвязанного поведения в "мы-группе», тем больше вероятность, что "мое" самотипизированное поведение достигнет желаемой цели. Однако нужно помнить, что в противоположность "мы-группе" может сформироваться "они-группа", в которой ожидания индивида не обязательно совпадут со взглядами "других", что окажется причиной возникновения недоверия между членами группы и, как следствие, конфликта.

Идеи повседневного мышления А. Шюца позволяют нам выделить следующие предпосылки возникновения доверия между властью и обществом в рамках конструкта «мы»:

1) доверие возможно во взаимоотношениях в рамках "мы-группы", сформированной на основе общей системы релевантностей и схожем понимании образа жизни, в котором “мои" ожидания в той или иной степени совпадают с ожиданиями "других";

2) членов "мы-группы" связывают схожие этические обычаи и взаимные моральные обязательства, отличные от тех установок, которые исповедуют представители "они-группы";

3) объектом знания для "мы-группы" выступают типичные конструкты образа жизни, взаимодействия со средой, типичные средства для достижения типичных целей в типичных ситуациях, а целью членов "мы-группы” становится проектирование и строительство образа жизни;

4) поведение членов "Мы-группы" осуществляется по типичному способу деятельности, типичным мотивам и установкам типа личности, определяемых исходя из принятой системы релевантностей и целевого образа жизни сообщества;

5) в процессе формирования и деятельности “мы-группы" накапливаются и применяются знания смыслов и наборов мотивов, управляющих действиями "других", на предмет повышения вероятности достижения желаемого образа жизни как цели деятельности "мы-группы" не только в интересах "других" (то есть партнеров), но и с учетом интересов простых граждан, с которыми взаимодействие происходит в настоящем времени;

6) поведенческие и личностные типовые конструкты в рамках взаимоотношений членов "мы-группа" институализированы в формате стандартов поведения, обуславливающих обычаи и традиции членов «мы-группы»;

7) взаимоотношения в рамках “мы-группы" подчиняются концепции "приемлемого риска", согласно которой признается право ее членов на непредумышленную ошибку, что подразумевает развитие системы взаимного общественного и государственного контроля, совершенствования коммуникаций для осуществления обратной связи между гражданами и властью с целью своевременного обнаружения и исправления возможных просчетов.

\section{Модель “мы-группа"}

Как уже отмечено в нашем исследовании, в период кризисных ситуаций усиливается единство между людьми и возрастает гражданская активность Это можно 
объяснить тем, что в форс-мажорных обстоятельствах власть и общество ассоциируют себя с принадлежностью к той или иной форме национального конструкта "мы-группа", в котором мораль начинает доминировать над интересами. Но как только угроза государству отступает, власть под давлением близких ей групп интересов вынуждена помещать мораль в прокрустово ложе формализма и прагматики.

Очевидно, что, когда внешние обстоятельства подталкивают общество к переходу в модель функционирования "мы-группа", мотивируя повышенную ответственность и целеустремленный настрой каждого, в том числе властного, участника, это самым позитивным образом влияет на эффективность деятельности социума в целом, так как вносит в повседневность дополнительный элемент энтузиазма и самоотверженности. Однако по окончании мобилизационного периода власть и общество в рутинной повседневности тоже взаимодействуют, но уже больше по линии "я" и "они". Таким образом, можно сказать, что наивысшая эффективность деятельности общества достигается в рамках национальной модели "мы-группа", функционирующей в стабильном состоянии в течение длительного периода времени.

Однако прежде чем мобилизовать социум на движение к этой модели, следует понять, что она из себя представляет, сформировать предпосылки для ее воспроизводства и затем имплантировать ее в существующую систему государственного управления, которая по настоящее время эволюционирует в парадигме, где публичная власть сама устанавливает границы своей ответственности, исходя из собственных представлений и не увязывая программы общественного развития с интересами рядовых граждан.

Из описания конструкта "мы-группа" становится понятно, что на сегодняшний день одноименная модель не может функционировать в национальном масштабе, поскольку в рамках российского социума отсутствует общая система релевантностей и схожее понимание общего образа жизни. Кроме того, недостаточно четко выявлены смыслы и наборы мотивов, управляющих действиями "других". Можно предположить, что существует некоторое количество "они-групп", имеющих морально-этические и типические установки, отличные от "мы-группы", но сами по себе они могут соответствовать каким-то другим "мы-группам".

Из этого следует, что конструирование "мы-группы" возможно не во всем обществе одновременно, а в каком-то его сегменте вокруг цели достижения образа жизни, приемлемого для данной части социума (по-другому-образа желаемого будущего). Соответственно, в обществе должна существовать возможность выявления круга потенциальных участников этого сегмента общества, поведение которых укладывается в типичные способы деятельности, типичные мотивы и установки типа личностей, определяемых из принятой для данной части общества системы релевантностей (иначе - общественных ценностей). Исходя из этого допущения, все общество можно представить состоящим из некоторого числа “Мы-групп" и "они-групп", причем их границы определяются как общей системой релевантностей и схожим пониманием образа жизни, так и поведенческими и личностными типовыми конструктами участников.

Так как все общество представляется набором различных "мы-групп" и "онигрупп", возникает резонный вопрос: а что будет "сшивать" социум в единый со- 
циальный организм, если власть и общество в России сегодня функционируют по правилам модели "я - они", не предполагающей наличие устойчивых доверительных отношений между ведущими ключевыми акторами?

Поскольку доверительные отношения могут возникнуть в "Мы-группе» на основе общей системы релевантностей и схожего понимания образа жизни, отдельные "мы-группы" общества должны принять национальную систему релевантностей и национальное понимание образа жизни, тем самым образуя внутри каждой “мы-группы" два взаимосвязанных уровня идентичности - национальный и входящий в него групповой. Те части социума, которые не введут в свой общественный дискурс национальный уровень идентичности, по умолчанию будут образовывать “они-группы". Кроме того, переход к функционированию общества по модели "мы-группа" не может осуществиться без введения в общественный дискурс норм морали как нравственного ограничителя эгоистических интересов взаимодействующих групп.

\section{Взаимосвязь морали и интереса в обществе}

Так как переход к модели "мы-группа" будет происходить во времени и пространстве, что означает длительную эволюционную трансформацию отношений в обществе, поиск приемлемого баланса интересов и моральных ограничителей ведущих акторов на долгосрочную перспективу возможен лишь в рамках общей системы координат, в которой интересы и мораль "соизмеряются" одной шкалой и синхронно "соизменяются" при подборе оптимального сценария государственного развития без утери субстанциального смысла утвержденных приоритетов. По сути дела, стоит задача объединить в новой модели общества "мы-группа" две противоположенные природы - мораль как инь (внутреннее самосознание) и интересы как ян (движение к новой сущности), поскольку только в синтезе морали и интересов может прогрессировать жизнь общества.

Интерес можно выразить в материальной сущности, сравнительно легко персонифицировать и измерить количественно, определяя результат его реализации в рублях, тоннах, километрах и т.д. с отнесением на конкретную личность или группу. Мораль как нематериальную сущность измерить много сложнее: каждая личность сама очерчивает границы своего морального пространства, в котором она ощущает обязанность доверять, проявлять лояльность и солидарность с другими, то есть связывать себя моральными узами самосознания [Штомпка, 2012], и не факт, что моральное пространство одной личности совпадает с моральным пространством другой. Однако при условном наложении этих моральных пространств, присущих разным членам общества, друг на друга, скорее всего, проявится общая зона, которую можно назвать “зоной морального согласия большинства", где количественно-качественными выражениями можно попробовать описать доминирующие отношения между акторами общественно-политического процесса в категориях доверия, лояльности и солидарности.

Если найти способ поместить доминирующие интересы ведущих акторов общества внутрь “зоны морального согласия большинства", то с учетом результатов исследования конструкта "мы-группа" основные характеристики модели общества «мы-группа" можно было бы описать следующим образом: 
- целью деятельности общества по модели "мы-группа" выступает проектирование и достижение образа будущего в интересах как членов группы (их еще можно обозначить как "команда") и их партнеров, так и граждан, не принимающих активное участие в жизнедеятельности "мы-группы", но заинтересованных в достижении образа будущего;

- формирование состава "мы-группа" осуществляется с учетом схожих ожиданий потенциальных участников, основанных на близком понимании системы принятых ценностей и образа желаемого будущего общества;

- групповые и личностные интересы в обществе "мы-группа" имеют схожие этические основания и взаимные моральные обязательства;

- взаимоотношения членов "мы-группы" осуществляются на основе общепринятых поведенческих и личностных норм, определяемых исходя из принятых В «мы-группе» ценностей и образа желаемого будущего общества, и закрепленных в формате стандартов поведения (кодекса поведения);

- межличностные отношения, в том числе между властью и гражданами, строятся на взаимном доверии и благожелательности;

- в "мы-группе" действует концепция "приемлемого риска", согласно которой за членами группы признается право непредумышленной ошибки и солидарная ответственность за возможные просчеты в процессе проектирования и достижения образа будущего;

- в процессе проектирования и достижения образа будущего общества происходит постоянное накопление знания смыслов и мотивов участников, вследствие чего может изменяться как состав "мы-группы", так и содержание системы релевантностей и образа будущего общества.

Вопрос о соразмерности и взаимовлиянии материальных и нематериальных сущностей в процессе поиска баланса интересов и морали в обществе следует рассматривать скорее в контексте рационального выбора приемлемого механизма нахождения согласия, чем в плане изучения культурологического генезиса моральных ценностей или принципов ресурсной зависимости акторов сетевых коалиций интересов. В этой связи акцент в настоящем исследовании сделан на анализе подходов к стратегии трансфера социума из текущего состояния к целевому, соответствующему желаемому образу всего общества в парадигме модели «мы-группа".

Прежде всего, необходимо определить образ целевого состояния общества, соответствующего желаемому в модели "мы-группа". В основном это целевое состояние видится близким к модели идеального общества, но так как каждая социальная страта - власть, бизнес, отдельные слои общества - в реальности понимает свое будущее, исходя из собственных субъективных интересов, их объективно существующий конфликт может быть урегулирован только при условии, если бенефициарами желаемого целевого состояния социума одновременно оказываются все его акторы: власть, бизнес, граждане. Рассмотрение образа желаемого целевого состояния общества через призму приобретения ведущими акторами соответствующих выгод в случае его достижения существенно облегчает задачу согласования интересов и морали, так как в рамках политического торга возможен обмен материальными и нематериальными ресурсами между заинтересованными сторонами во имя коллективного выбора. 
Ведя торг по вопросу размера своей доли общественного пирога, каждый заинтересованный актор понимает, что его партнеры по торгу-такие же люди, обуреваемые человеческой субъектностью и живущие в сетевом пространстве ролей и комбинаций статусов, что делает их поведение все менее предсказуемым [Мертон, 2006]. Непредсказуемость порождает неуверенность в отношении действий, предпринимаемых людьми, все это усугубляется воздействием со стороны отдельных технологий, создающих новые угрозы и опасности. Глобальность функционирования сложных институциональных, организационных и технических систем не позволяет индивидуумам своевременно вникнуть в суть мотивации акторов социального мира, а возрастающая анонимность неконтролируемых обществом распорядителей ресурсов, от которых зависит человеческое благополучие, дополняется чуждым воздействием на наш "знакомый" мир со стороны внешних культурных пространств. В этих условиях доверие становится тем «необходимым ресурсом, который позволяет справиться с присутствием в нашей жизни чужих" [Штомпка, 2012: 59].

Ощущение недолговечности ролей в обществе и неоднозначность будущего привели к осознанию того, что "...чем выше неопределенность и реальнее перспектива достижения ролевых ожиданий в рамках переговорного процесса, тем больше возможностей для развития доверия как формы общественных отношений" [Seligman, 1997; 39]. Такой вывод указывает обществу способ поиска баланса интересов и морали в том или ином проекте на соответствующей переговорной площадке с участием заинтересованных акторов. В этом смысле доверие к власти становится тем нематериальным ресурсом, по поводу которого на такой площадке возможен торг между населением и властью при согласовании желаемого целевого состояния общества.

Доверие в политике становится необходимым условием жизнеспособности политической системы, важным аспектом гражданского общества, скрепленного межличностными узами горизонтального доверия и вертикалью доверия к публичным институтам, а также основной составляющей социального капитала, представляющего собой сеть спонтанных добровольных обществ, проникнутых атмосферой доверия [Putnam, 1995]. Обменивая в переговорном процессе собственные ресурсы доверия наряду с другими материальными и нематериальными сущностями на долю общественного "пирога", группы интересов власти, общества и граждан обретают статус бенефициаров социальных благ, создаваемых в результате реализации задуманной общественно-политической программы или проекта и имеющих, как правило, национальный и региональный аспекты.

Обмен предполагает оценку ресурса доверия в измеримых категориях для того, чтобы в переговорном процессе в результате социального конструирования возникла возможность достижения доверительных отношений через согласование границ собственных уступок. В настоящее время в основном используются методы оценки политического доверия, базирующиеся на измерении социально-экономических критериев, проведении социологических опросов населения, анализе динамики гражданской активности и политического участия граждан в жизни государства и других приемах [Черницына, 2016]. Однако все эти подходы характеризуют состояние власти и общества в конкретном месте и в определенном периоде социологического замера. Знание текущего и прошлых уровней 
доверия общества к власти дает возможность политическим экспертам провести экстраполяцию исторических данных при допущении, что будущее доверие будет соответствовать характеру его поведения в прошлом.

Вместе с тем в реальном мире внутренние и внешние факторы изменяются настолько быстро и непредсказуемо, что судить о будущем доверительных отношений по линии "власть - бизнес - общество", полагаясь только на соблюдение принципов эволюционности и преемственности, было бы неразумно. Поэтому вполне логично поставить вопрос о необходимости овладеть искусством управления доверием, обращая интересы власти, бизнеса и общества как бенефициаров социальных благ в будущее целевое состояние социальной системы, располагающееся в "зоне морального согласия большинства". Конструируя образ целевого состояния социума, в котором интересы и мораль смогут находиться в сбалансированной гармонии по волеизъявлению ее акторов, власть, бизнес и гражданское общество своим согласием скрепляют в единый организм на долгосрочный период зависимые от их поведения элементы системы государственного управления. В этом смысле можно определить результат деятельности социума по модели «мы-группа" как выполнение общественного договора, установившего, что в результате публичного переговорного процесса между властью, бизнесом и гражданами достигнуто добровольное согласие по ключевым положениям образа целевого состояния общества и условиям его достижения по модели "мы-группа", которые реализованы совместными усилиями заинтересованных акторов.

\section{Предпосылки формирования модели "мы-группа"}

Форма соглашения, называемая общественным договором, имеющая целью создание целостного общества, устойчивого государства на основе как совпадающих, так и конкурирующих интересов, известна в политической науке еще со времен Т. Гоббса, который признавал договорную теорию происхождения государства на основании добровольного соглашения между народом и верховной властью. Однако генезис понятия "общественный договор" не рассматривается в качестве предмета настоящей статьи. Применительно к исследуемой теме нас интересуют лишь роль и место общественного договора в модели социума "мы-группа", который фиксирует условия соглашения по поводу сосуществования индивидов и групп в обществе по отдельному вопросу формирования и достижения образа его будущего. Такая форма соглашения в юриспруденции известна под названием modus vivendi. Она не предполагает закрепление временного общего взгляда всех субъектов и групп на то, какой должна быть справедливость, а базируется на изначальном, существовавшем еще до начала формирования такого соглашения объективном реализме присутствия несогласия и плюрализма мнений участников.

Т. Фоссен предложил следующие базовые требования, которым отвечает состояние modus vivendi [Fossen, 2019]:

- соответствие критериям практической достижимости, так как достичь modus vivendi проще, чем воплотить в жизнь "идеальное общество", в котором всегда найдутся исключенные и маргинальные участники;

- соответствие нормативной валидности, согласно которой ни одна концепция справедливости не является валидной, то есть изначально не учитывает в полной 
мере плюрализм принятых в обществе ценностей [Gray, 2000], при этом здравый смысл диктует временный запрет на любые модели справедливости во имя достижения мирного урегулирования конфликта [Horton, 2006];

- соответствие принципу избегания политической угрозы, заключающемуся в достижении компромисса между "начерно определенным миром" и справедливостью, установленной на основе гибкого соблюдения определенных условий.

По Т. Фоссену власть - реальный участник переговоров по достижению согласия, равный другим субъектам, а это означает, что при разборе политической ситуации (достижение образа будущего общества - это политический процесс) власти следует прийти к позиции, идентичной видению других акторов. Из этого Т. Фоссен делает важнейший вывод о том, что общественный договор в смысле modus vivendi становится не формой поиска согласия, а формой политического выживания каждого из участников.

Этот вывод позволяет нам сделать допущение, что справедливость как результат взаимодействия субъектов и групп, зафиксированная в итоговом тексте общественного договора, на весь период процесса достижения образа будущего общества гарантирует соблюдение политических интересов акторов, принимавших участие в его формировании.

В этом смысле общественный договор в формате modus vivendi выступает для власти как политической силы действенным инструментом согласования с обществом условий, выполнение которых позволит ей сохранить рычаги управления на данной территории в течение действующего электорального цикла и заложить весомые предпосылки для своего переизбрания. По сути, общественный договор в этом случае выступает как политическая декларация действующей власти, в которой она, по согласованию с бизнесом и обществом, излагает свою стратегию, направленную на удержание политического руководства.

Исходя из допущения, что функционирование оптимальной модели общества "мы-группа" возможно на основании общественного договора, рассмотрим условия, при наличии которых она будет не только работоспособной, но и обеспечит повышение эффективности системы государственного управления. Следует отметить первостепенное значение формирования долгосрочной доверительной основы отношений между властью, бизнесом и обществом, которая опирается на "стратегию неумолимости", пришедшую в политологию из теории игр. Эта стратегия подразумевает совместную работу участников, продолжающуюся до тех пор, пока ни одна из сторон не нарушает начального соглашения. В случае нарушения одной из сторон своих обязательств сотрудничество прекращается навсегда [Dasgupta, 2007]. Угроза включения у противоположенных сторон "стратегии неумолимости" и возникновения при этом потерь от недополучения всех будущих выгод, возможных при долгосрочном сотрудничестве, способствует удержанию акторов от нарушения договоренностей. В этом случае возникает и работает "социальная норма" как базис выстраивания долгосрочного доверительного сотрудничества в противоположность стратегии подчинения закону.

В рамках функционирования модели "мы-группа" важнейшим условием сохранения устойчивых долгосрочных доверительных отношений власти, бизнес-сообщества и гражданских структур выступает ответственность всех действующих акторов за вы- 
полнение достигнутых договоренностей в соответствии с концепцией "социальной нормы". Групповая ответственность заинтересованных в достижении желаемого целевого состояния общества акторов - это принципиальное переустройство внутренних форм контроля своей деятельности у индивидуума, действующего как представитель актора, приобретение им таких черт характера, при которых все принимаемые решения соотносятся с собственной и групповой системами ценностей, формируя тем самым чувство ответственности за последствия своих поступков. Ответственность при таком подходе отличается от обязанности отсутствием внешней принудительной силы, так как ответственность - это скорее проявление внутренне осознанного долга по выполнению требований, осмысленно принимаемых добросовестным индивидом. Об уровне ответственности представителей власти, бизнеса и гражданского общества можно судить лишь по ее проявлению в деятельности, поступках, отношении к людям, но нужно помнить, что внешне наблюдаемое поведение не всегда будет соответствовать скрытым внутренним ценностным установкам акторов, формально действующих в русле концепции "социальной нормы".

Из этого следует, что в контексте формирования и выполнения общественного договора по воплощению модели "мы-группа" стоит задача не разоблачения ментальной ценностной базы отдельных личностей, принимающих участие в совместной деятельности, а концентрация усилий на обеспечении позитивных действий даже внешне заинтересованных, но внутренне неуверенных акторов, не до конца разделяющих общественные ценности "зоны морального согласия большинства", тем не менее поддающихся внешнему принуждению для совершения поступков, направленных на достижение желаемого целевого состояния общества.

Из этого необходимого компромисса следует важный вывод: в работу по формированию общественного договора по поводу модели общества "мы-группа" нужно стремиться вовлекать не только акторов, имеющих относительно сходные ценностные установки, сравнительно близкие взгляды на образ общего будущего и на программу по его достижению, но и тех, критерием полезности которых, несмотря на подсказки "внутреннего голоса", становится их договороспособность во имя конструктивной деятельности, нацеленной на коллективный результат.

Данный подход задает вектор поиска критериев и порядка отбора представителей власти, бизнеса и гражданского общества для участия в публичном процессе формирования и достижения целевого состояния социума по модели "мы-группа", осуществляемого на принципах открытости, справедливости и самоорганизации при содействующей роли государственных структур. В этом смысле партисипаторная государственная управляемость открывает новые возможности гражданского участия в публичной политике и управлении на основе представления государства как платформы, реализуемого в единстве с новым совещательным характером политического режима в целом [Сморгунов, 2019].

С точки зрения критериев пространства и способа организации взаимодействия для целей формирования и реализации образа целевого состояния общества особый интерес представляет так называемая краудсорсинговая платформа (crowdsourcing platform), в рамках которой правительство налаживает открытое сотрудничество с гражданами, бизнесом, другими неправительственными организациями, выступая в качестве организатора или хаба для 
экосистемного взаимодействия ${ }^{6}$. Как показывает исследование, проведенное компанией Accenture, эта платформа лучше всего подходит для стран, в которых новые политические вопросы требуют инновационных решений с участием гражданского общества ${ }^{7}$, что удовлетворяет и новаторским требованиям по реализации модели "мы-группа".

Проект российского государства как платформы впервые был предложен Центром стратегических исследований в 2018 г. [Буров и др., 2018]. Однако граждане и бизнес в нем оказались представлены лишь как потребители государственных услуг, соответственно, система взаимодействия ориентировалась в основном на регистрацию их пожеланий, которые (возможно) будут более полно учтены государственным управлением [Сморгунов, 2019].

Выстраивание же доверительных отношений между властью, бизнесом и обществом, как было отмечено ранее, предполагает использование более жесткого формата взаимодействия на основе "стратегии неумолимости", которая не приемлет применения терминологии "возможно" при учете мнения граждан и бизнеса относительно образа целевого состояния общества и путей его достижения. Включение "стратегии неумолимости" подразумевает наличие четких обязательств заинтересованных акторов по поводу содержания качественных и количественных показателей, характеризующих модель общества "мы-группа".

Для урегулирования этого противоречия вывод представителей власти, бизнеса и гражданского общества на краудсорсинговую правительственную платформу может осуществляться в два этапа. На первом этапе власть размещает в публичном информационном пространстве - на сайте специально созданного хаба для экосистемного сетевого взаимодействия - свои предложения, содержащие основные положения коллективной системы ценностей и образа целевого состояния общества, с целью всестороннего обсуждения, а также выявления наиболее активных акторов, высказывающих разумные мысли и расположенных к творческому и конструктивному сотрудничеству с властью. На втором этапе, после обработки предварительных результатов обсуждения, власть организует формирование и подписание общественного договора по достижению модели «мы-группа" с участием наиболее энергичных, креативных и ответственных представителей бизнеса, гражданского общества, других неправительственных организаций. Отбор подписантов общественного договора со стороны бизнеса и гражданского общества должен проводиться с учетом мнения представителей исполнительной и законодательной власти, общественных палат, ассоциаций бизнеса, гражданских структур и т. д.,однако в ходе обсуждения его текста возможно приглашение и других участников по инициативе заинтересованных групп граждан.

\section{Формирование регионального общественного договора}

При формировании общественного договора, определяющего деятельность региональной «мы-группы", могут быть рассмотрены следующие вопросы:

\footnotetext{
${ }^{6}$ Four platforms for government//Accenture. 2018. August 31. URL: https://www.accenture.com/us-en/insights/ public-service/four-platforms-for-government (дата обращения: 25.04.2021).

7 Government as a Platform //Accenture. 2018. URL: https://www.accenture.com/_acnmedia/PDF-83/AccentureGaaP-2018-Readiness-Index.pdf\#zoom=50 (дата обращения: 25.04.2021).
} 
1) Образ желаемого целевого состояния общества, выраженный в качественных и количественных показателях, а также структурированный по стратегическим направлениям:

- социально-экономическому направлению, предполагающему достижение социально-экономических показателей, декомпозированных из национальных целей и приоритетов, а также показателей, обеспечивающих решение ключевых региональных и муниципальных проблем;

- социальному направлению, предполагающему согласование и выполнение "кодекса поведения" власти, бизнеса и структур гражданского общества, направленных на формирование, поддержание и укрепление доверительных отношений.

2) "Дорожная карта", определяющая направления деятельности власти, бизнеса и гражданского общества по достижению желаемого целевого состояния общества.

3) Проект общественного договора между властью, бизнесом и гражданским обществом, определяющий систему коллективных ценностей и образ желаемого целевого состояния социума, права и обязанности ведущих акторов и программу под условным названием "Общественное доверие», направленную на поддержание и укрепление доверительных отношений между акторами, а также на упреждение угроз и вызовов социально-политической стабильности.

Предлагаемая последовательность действий по формированию и развитию доверительных отношений в сфере государственного управления неизбежно ставит вопрос об объективной оценке этих отношений в процессе выполнения общественного договора, принимаемой всеми заинтересованными акторами. В этой связи за исходный посыл можно взять замысел Указа Президента России от 25.04.2019 № $193^{8}$, а также уточняющего его Указа Президента России от 04.02.2021 №689, которым установлен интегральный показатель “уровень доверия к власти", базирующийся на достижении двадцати основных социально-экономических показателей (уровень реальной среднемесячной заработной платы, уровень бедности, качество окружающей среды, уровень образования и др.). Идея данных указов состояла в том, что добросовестная деятельность региональных властей по достижению наивысших результатов по указанным показателям будет автоматически приводить к увеличению уровня доверия населения к власти.

Отчасти в этом есть определенный смысл: некоторые исследования показали, что граждане, как правило, больше довольны таким правительством, которое упорно работает на их благо при том, что правительство действительно выполняет то, что оно намеревалось сделать ${ }^{10}$. Однако факт в том, что в исследованных

\footnotetext{
8 Указ Президента Российской Федерации от 25 апреля 2019 г. № 193 «Об оценке эффективности деятельности высших должностных лиц (руководителей высших исполнительных органов государственной власти) субъектов Российской Федерации и деятельности органов исполнительной власти субъектов Российской Федерации"//Kremlin. ru. URL: http://www.kremlin.ru/acts/bank/44185 (дата обращения: 25.04.2021).

9 Указ Президента Российской Федерации от 4 февраля 2021 года №68 "Об оценке эффективности деятельности высших должностных лиц (руководителей высших исполнительных органов государственной власти) субъектов Российской Федерации и деятельности органов исполнительной власти субъектов Российской Федерации".

${ }^{10}$ Blanding M. (2014) How Government Can Restore the Faith of Citizens. Harvard Business School. 13 January. URL: https://hbswk.hbs.edu/item/how-government-can-restore-the-faith-of-citizens (accessed: 25.04.2021).
} 
примерах граждане были отстранены от процесса принятия решения по существу тех или иных мероприятий, направленных на их благо, за них это делали представители правительства, которые могли понимать благо людей со свойственной чиновникам избирательностью. Поэтому приведение граждан в состояние сопричастности при совместном с властью определении уровня основных социально-экономических показателей развития той или иной территории будет способствовать более пристальному вниманию со стороны заинтересованного общества за исполнением согласованных мероприятий и, следовательно, к более точной оценке степени доверия населения к власти и своей гражданской ответственности за достигнутый результат.

Такой подход позволяет вывести универсальный способ оценки уровня доверия к власти: если власть, бизнес и представители гражданского общества достигли договоренности по желаемому уровню основных социально-экономических показателей, рассчитанных по специальной методике ${ }^{11}$ и входящих в программу "Общественное доверие» (будет их двадцать или другое количество - решать участникам общественного договора), то этот желаемый целевой уровень каждого показателя можно принять за $100 \%$. Соответственно, текущий уровень показателя, рассчитанный по той же самой методике, будет составлять долю от желаемого целевого уровня, выраженную в процентах. Среднеарифметическое значение по всем основным социально-экономическим показателям, соответствующим желаемому целевому уровню, можно считать неким опосредованным максимальным уровнем доверия населения к власти по социально-экономическому направлению, связанному с национальными целями и приоритетами.

Аналогичный подход можно применить и при оценке уровня доверия населения к власти по социально-экономическому направлению, связанному с решением ключевых региональных и муниципальных проблем. Отличие будет заключаться в том, что участники общественного договора сами должны договориться о перечне тех ключевых проблем региона или муниципалитета, который должны будут внести в общественно-политическую повестку дня, а также об уровне социально-экономических показателей, характеризующих достижение желаемого целевого состояния, обеспечивающего решение этих ключевых социально-экономических проблем.

Если оценка уровня доверия населения к власти по социально-экономическому направлению возможна с опорой на ряд показателей, выведенных из эмпирического знания природы их происхождения, то оценка доверия по социальному направлению в бо́льшей степени базируется на результатах субъективного анализа действий участников общественного договора по выполнению достигнутых договоренностей, с поправкой на личное восприятие субъекта договорной деятельности. Профессионализм, компетентность, содержательная деятельность участников общественного договора, степень развитости обратной связи между

\footnotetext{
${ }_{11}^{11}$ Методика расчета социально-экономических показателей, используемых для оценки эффективности деятельности органов исполнительной власти субъектов Российской Федерации, утверждена постановлением Правительства Российской Федерации от 19 апреля 2018 года № 472 «Об осуществлении мер по реализации государственной политики в сфере оценки эффективности деятельности органов исполнительной власти субъектов Российской Федерации и признании утратившими силу некоторых актов Правительства Российской Федерации" // Government. ru. URL: http://government.ru/docs/32367/ (дата обращения: 25.04.2021).
} 
ними, учет общественного мнения, открытость и прозрачность взаимоотношений между властью, бизнесом и обществом и многие другие факторы, конечно же, имеют существенное значение при оценке уровня доверия к политическим институтами, однако в конечном итоге только наглядные результаты деятельности ведущих акторов могут стать основным критерием, по которому следует оценивать эффективность деятельности власти.

Таким образом, можно допустить, что интегральный уровень доверия населения к власти состоит из нескольких компонентов: успехов по достижению социальноэкономических показателей из федерального списка, результатов реализации региональной общественно-политической повестки дня по решению ключевых местных проблем, а также фактов исполнения конкретных социальных обязательств, принятых на себя властью, бизнесом и обществом при подписании общественного договора. Оказывая влияние на параметры образа целевого состояния общества, а также воздействуя на динамику изменений компонентов, составляющих интегральный уровень доверия населения к власти, власть тем самым демонстрирует свою способность решать сложные социально-экономические проблемы путем содействия, оказания помощи, координируя усилия всех заинтересованных акторов, по сути, управляя процессом завоевания политического доверия к самой себе, усиливая факторы, вызывающие позитивные эмоции у граждан, и ослабляя воздействие движущих сил, последствия проявления которых негативно воспринимаются людьми, тем самым принуждая все элементы государственной машины действовать синхронно, солидарно, социально ответственно.

\section{Модель "мы-группа" в системе государственного управления}

Внедряя модель "мы-группа" в систему государственного управления, власти предстоит осознать, что речь идет об укоренении системы долгосрочного стратегического сотрудничества с населением и рыночными институтами, выстроенной на доверительной основе, способной тонко настраиваться под нужды общества в зависимости от внутренних и внешних обстоятельств во имя достижения рациональных и справедливых целей и приоритетов. При таком подходе для формирования доверия населения к политическим институтам в рамках действующей системы государственного управления следует рассмотреть вопрос о целесообразности введения отдельной задачи по идентификации показателя доверия к власти, уровень которого в случае его роста будет придавать политическому руководству чувство уверенности в правильности своих действий, а в случае снижения - станет сигналом о необходимости внесения корректировки в избранный курс.

Необходимо подчеркнуть, что решение задачи формирования доверия к власти не должно приводить к манипуляции сознанием граждан под воздействием популистских решений, принимаемых властью для достижения каких-либо своих тактических выгод. Долгосрочный характер доверительных отношений предполагает эволюционное наращивание усилий со стороны власти по согласованию общественного договора, разработанного на принципах "социальной нормы" ради достижения общей цели - повышения качества жизни граждан. Исходя из ранее высказанного представления о краудсорсинговой платформе, в этом случае разработку общественного договора целесообразно проводить на специально 
организованном хабе для экосистемного сетевого взаимодействия. Стартовой точкой для запуска процесса формирования и реализации общественного договора могло бы стать создание открытой информационно-коммуникативной площадки на базе некой уже действующей организации, например, общественной палаты, обладающей навыками провайдера сетевого взаимодействия. На этой площадке в рамках процесса формирования и реализации общественного договора в непосредственный контакт будут вступать граждане как индивидуумы со своим характером и компетентностью; представители социальных групп, связанных с разными идентичностями; представители предприятий и организаций, имеющих свои структуры, нормы и правила; представители государственных институтов со своими общественными установками.

Однако еще до принятия политического решения по запуску процесса выстраивания доверительных отношений между властью, бизнесом и обществом самой власти нужно четко ощутить, что она все же готова помогать гражданам прокладывать мост над пропастью неуверенности, разделяющей чиновников и общество, генерируя свое доверие партнерам по общественному договору, даже несмотря на возможные негативные для власти политические последствия проявления инициативности граждан, связанные с их активным вовлечением в общественную деятельность.

\section{Список литературы (References)}

Буров В.В., Петров М.В., Шклярук М. С., Шаров А. В. "Государство-как-платформа»: Подход к реализации высокотехнологичной системы государственного управления // Государственная служба. Теория и практика управления. 2018. Т. 20. № 3. C. 6-17. URL: https://pa-journal.igsu.ru/articles/6004/ (дата обращения: 25.04.2021).

Burov V.V., Petrov M. V., Shklyaruk M. S., Sharov A. V. (2018) "State-As-Platform": An Approach to Implementing a High-Tech Public Administration System. Public Adminisfration. Vol. 20. No. 3. P. 6-17. URL: https://pa-journal.igsu.ru/articles/6004/ (accessed: 25.04.2021). (In Russ.)

Громыко А. А. Коронавирус как фактор мировой политики // Научно-аналитический вестник Института Европы РАН. 2020. № 2. С. 4-13. http://doi.org/10.15211/ vestnikieran22020413.

Gromyko A. A. (2020) Coronavirus as a Factor in World Politics. Scientific and Analytical Herald of the Institute of Europe RAS. No. 2 P. 4-13. http://doi.org/10.15211/vestnikieran22020413. (In Russ.)

Мертон P. Социальная теория и социальная структура. М.: ACT, 2006. Merton R. (2006) Social Theory and Social Structure. Moscow: AST.

Разин А. В. Личный интерес в морали // Вестник РУДН. Серия Философия. 2013. № 3. C. 12-27. URL: http://journals.rudn.ru/philosophy/article/view/11418/ru_RU (дата обращения: 25.04.2021).

Razin A. V. (2013) Personal Intrest in Moral. Rudn Journal of Philosophy. No. 3. P. 1227. URL: http://journals.rudn.ru/philosophy/article/view/11418/ru_RU (accessed: 25.04.2021). (In Russ.) 
Российское общество и государство в условиях пандемии: социально-политическое положение и демографическое развитие Российской Федерации в 2020 году / под ред. Осипова Г.В., Рязанцева С. В., Левашова В. К., Ростовской Т. К. М.:Перспектива, 2020. URL: http://испи.рф/wp-content/uploads/2020/12/Российскоеобщество-и-государство-в-условиях-пандемии.pdf (дата обращения: 25.04.2021). Osipov G. V., Ryazantsev S. V., Levashov V. K., Rostovskaya T. K. (eds.) (2020) Russian Society and the State in the Context of a Pandemic: The Socio-Political Situation and Demographic Development of the Russian Federation in 2020. Moscow: Perspektiva. URL: http://испи.рф/wp-content/uploads/2020/12/Российское-общество-игосударство-в-условиях-пандемии.pdf (accessed: 25.04.2021). (In Russ.)

Сморгунов Л.В. Партисипаторная государственная управляемость: платформы и сотрудничество // Власть. 2019. Т. 27. № 5. С. 9-19. http://doi.org/10.31171/ vlast.v27i5.6712.

Smorgunov L. V. (2019). Participatory Governance: Platforms and Collaboration. Vlast. Vol. 27. No. 5. P. 9-19. http://doi.org/10.31171/vlast.v27i5.6712. (In Russ.)

Фукуяма Ф. Доверие: социальные добродетели и путь к процветанию. М. : АСТ : Ермак, 2004.

Fukuyama F. (2004). Trust: The Social Virtues and the Creation to Prosperity. Moscow: AST; Ermak.

Черницына Е. Н. Политическое доверие: как его измерить? // Государственное управление. 2016. Вып. № 54. С. 130-145. URL: http://e-journal.spa.msu.ru/ vestnik/item/54_2016chernitsyna.htm (дата обращения: 28.04.2021).

Chernitsyna E. N. (2016) Political Trust: How to Measure It? Public Administration. No. 54. P. 130-145. URL: http://ee-journal.spa.msu.ru/vestnik/item/54_2016chernitsyna.htm (accessed: 28.04.2021). (In Russ.)

Чупров В. И., Зубок Ю. А., Романович Н. А. Доверие в саморегуляции изменяющейся социальной реальности. М.: Норма, 2019.

Chuprov V.I., Zubok Yu.A., Romanovich N. A. (2019) Trust in Self-Regulation of Changing Social Reality. Moscow: Norma.

Штомпка П. Доверие-основа общества / пер. с пол. Н. В. Морозовой. М. :Логос, 2012. Sztompka P. (2012) Zaufanie - fundament społeczeństwa. Transl. from Polish N. V. Morozova. Moscow: Logos.

Шюц А. Структура повседневного мышления // Социологические исследования. 1988. № 2. C. $129-137$.

Schütz A. (1988). The Structure of Everyday Thinking. Sociological Studies. No. 2. P. $129-137$.

Dasgupta P. (2007) Economics: A Very Short Introduction. New York, NY: Oxford University Press.

Fossen T. (2019) Modus Vivendi Beyond the Social Contract: Peace, Justice, and Survival in Realist Political Theory. In: Westphal M., Horton J., Willems U. (eds.) 
The Political Theory of Modus Vivendi. Cham: Springer. P. 111-127. https://doi. org/10.1007/978-3-319-79078-7_7.

Gray J. (2000) Two Faces of Liberalism. Cambridge: Polity Press.

Horton J. (2006) John Gray and the Political Theory of Modus Vivendi. Critical Review of International Social and Political Philosophy. Vol. 9. No. 2. P. 155-69. https://doi. org/10.1080/13698230600654993.

Putnam R. D. (1995) Turning In, Turning Out: The Strange Disappearance of Social Capital in America. PS: Political Science and Politics. Vol. 28. No. 4. P. 664-683. https://doi.org/10.1017/s1049096500058856.

Seligman A. B. (1997) The Problem of Trust. Princeton, NJ: Princeton University Press. 